\title{
Distribution of ferritin, transferrin and lactoferrin in breast carcinoma tissue
}

\author{
R ROSSIELLO, MV CARRIERO, ${ }^{*}$ GG GIORDANO* \\ From the Institute of Anatomic Pathology, University of Naples, and the *Division of Anatomic Pathology, \\ National Institute of Tumors, Naples
}

SUMMARY An immunoperoxidase staining technique was used for detecting three major iron binding proteins (ferritin, transferrin and lactoferrin) in 40 breast carcinoma cases and six benign breast proliferative lesions.

Ferritin staining was detected mainly in connectival stroma and in histiocytes surrounding neoplastic cells. Few and faint ferritin positivities were also detected in neoplastic cells of 20 carcinoma cases. Transferrin was found inconsistently in myoepithelial cells surrounding normal ductules, or around neoplastic ducts of ductal in situ carcinoma. In eight carcinoma cases, transferrin staining was also positive in neoplastic cells. Lactoferrin was detected only in normal breast epithelial cells and in benign breast proliferative lesions.

These immunohistochemical findings may suggest that raised serum ferritin concentrations in breast carcinoma patients might be attributed to stromal reaction rather than to tumour synthesis. Transferrin staining of neoplastic cells in these carcinoma cases appears to be very intriguing, particularly since transferrin is considered an obligate requirement for growing cells, and transferrin receptors have been demonstrated only in dividing cells. On the basis of the immunohistochemical data, lactoferrin might be used as a pointer to benign lesions.

Ferritin, lactoferrin and transferrin are the three major iron-binding proteins in man. Until recently the clinical interest for these proteins was mainly confined to their role in iron transport and/or storage.

Nevertheless, increased serum ferritin concentrations have been found in a wide variety of malignant states including Hodgkin's disease, leukaemia, carcinoma of breast, pancreas, stomach and colonrectum..$^{68101219}$

Metabolic disorders in mononuclear phagocytic cells, lymphocytes or macrophages synthesis, tissue damage and tumour synthesis have been suggested as an explanation for this increase in ferritin serum concentrations in malignancy. ${ }^{2} 6$ 8-10 12 15 172122

On the other hand, raised transferrin serum concentrations and transferrin receptors have been demonstrated in breast carcinoma. ${ }^{3}{ }^{5} 1116$

Lactoferrin, like transferrin, is considered to play an important role in iron transport in human breast and other glandular tissues. ${ }^{13}{ }^{14} 20$

In a previous study, ${ }^{13}$ transferrin was found, by an

Accepted for publication 15 August 1983 immunoperoxidase method, mainly in periductular myoepithelial mammary cells, whereas ferritin was detected in periacinar, and lactoferrin in acinar cells.

In view of an increased interest in oncology for these iron-binding proteins, we have investigated ferritin, transferrin and lactoferrin distribution in breast carcinoma by an immunoperoxidase method.

\section{Material and methods}

Forty cases of breast carcinoma (31 invasive ductal), three in situ ductal, three lobular invasive and three mucoid carcinoma cases) and six benign neoplastic lesions (three fibroadenoma and three fibrocystic disease cases) were included in this study.

Tissue specimans were frozen in isopentane, cooled with liquid nitrogen or fixed in Bousin and in $10 \%$ buffered formalin, and then proccessed routinely. Both procedures gave similar results, although the staining generally appeared more intensive with Bouin's fixative.

Ferritin, lactoferrin and transferrin (Dako antisera) identification was carried out by immunoperoxidase, PAP method, according to Taylor ${ }^{18}$ with 


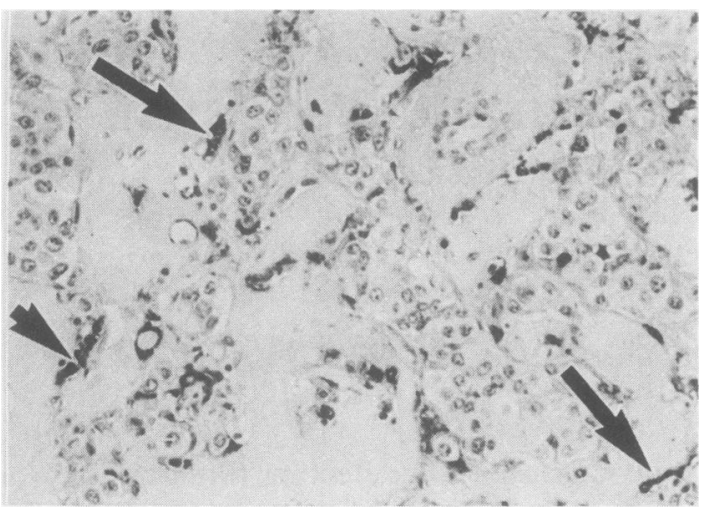

Fig. 1 Ferritin in invasive ductal carcinoma. Prevalent distribution of ferritin staining in connectival stroma PAPHaematoxylin $\times 100$.



Fig. 2 Ferritin in invasive ductal carcinoma. Few histiocytes surrounding neoplastic cells show an intensive ferritin staining PAP-Haematoxylin $\times 250$.

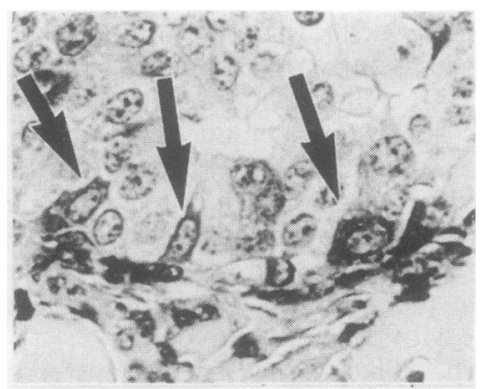

Fig. 3 Ferritin in invasive ductal carcinoma: Faint ferritin staining in some neoplastic cells. PAP-Haematoxylin $\times$ 250.

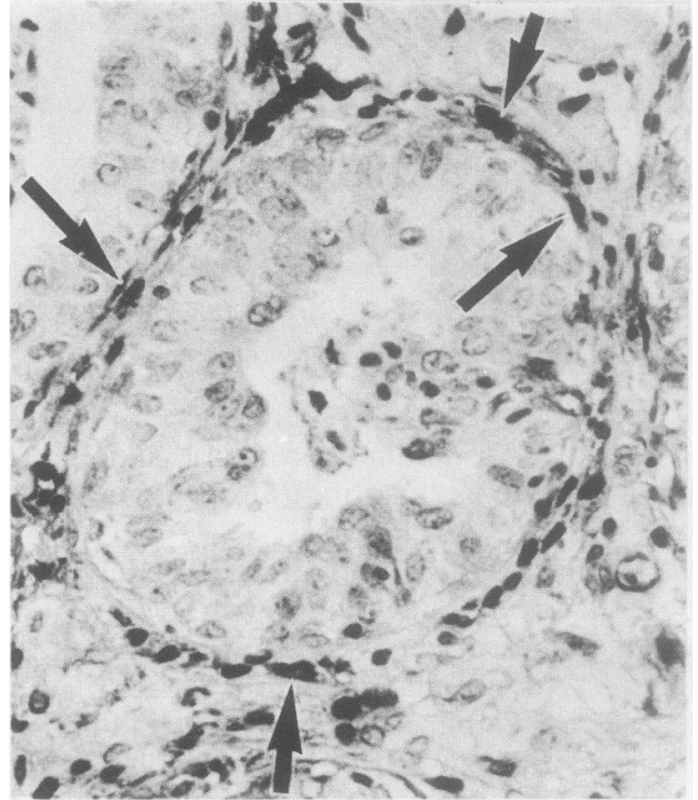

Fig. 4 Transferrin in intraductal carcinoma. Spindleshaped cells, around neoplastic ducts or in connectival stroma display intensive staining. PAP-Haematoxylin $\times$ 250.
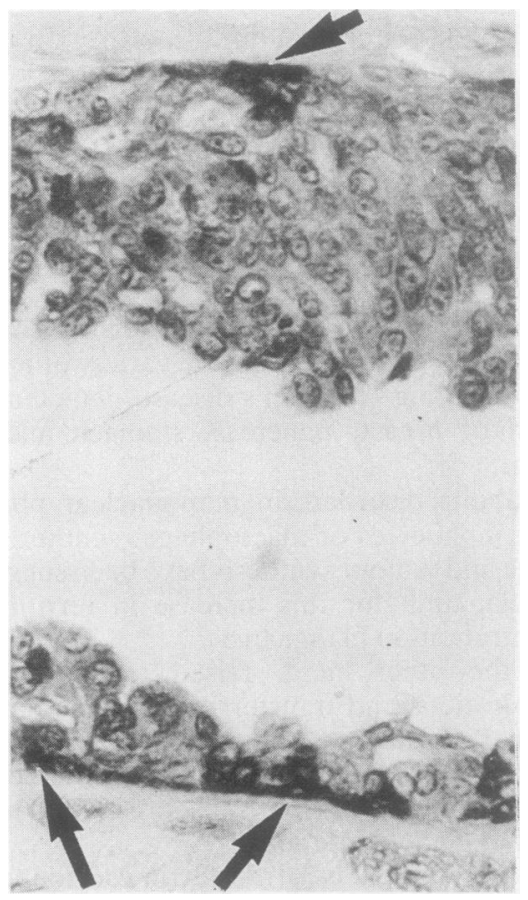

Fig. 5 Transferrin in a "clinging" carcinoma. Transferrin positive cells are mainly arranged at the periphery of neoplastic lesion. PAP-Haematoxylin $\times 250$. 


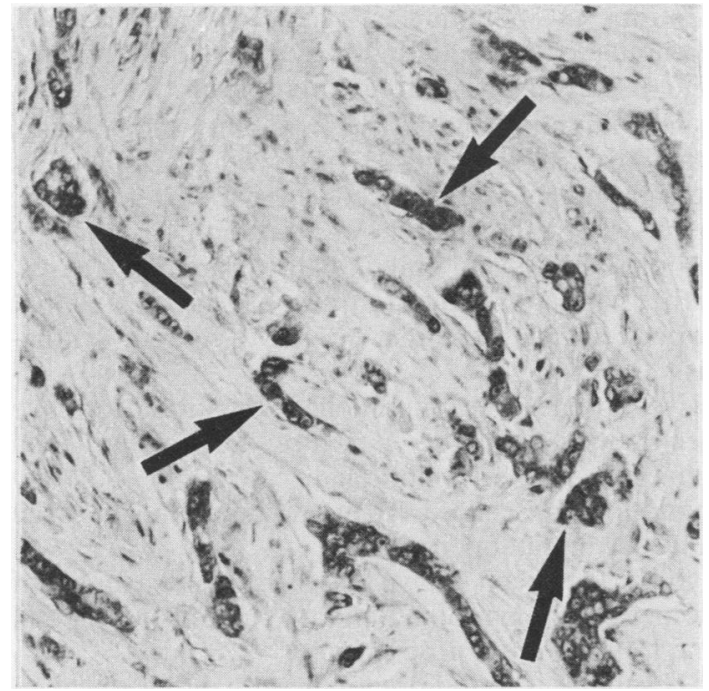

Fig. 6 Transferrin in invasive ductal carcinoma. Several neoplastic cells show a variable transferrin staining PAPHaematoxylin $\times 100$.

minimal modifications as previously reported. ${ }^{4}$

The sections were sequentially incubated for 20-30 min at room temperature with each of following

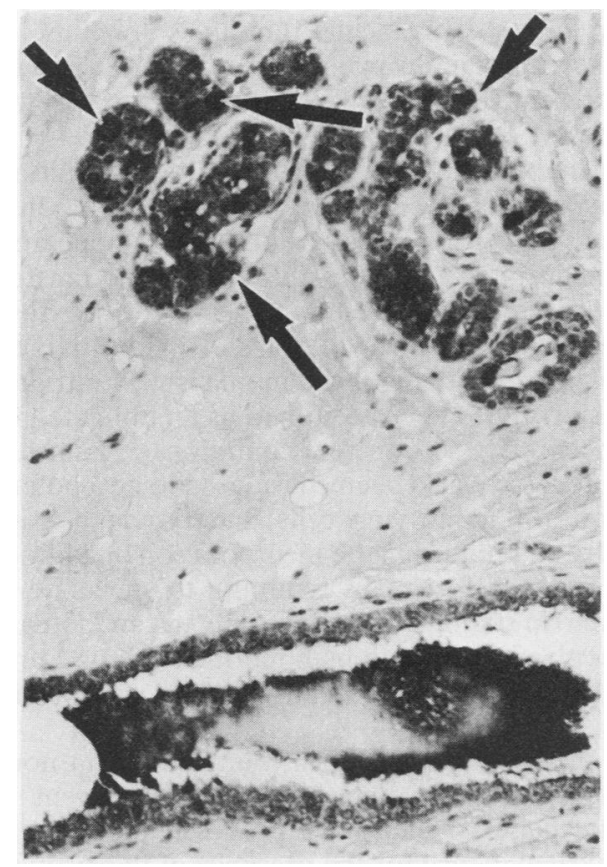

Fig. 7 Lactoferrin in a lobular unit. Secretory lactoferrin positive material may be observed within the wide ductal lumen. PAP-Haematoxylin $\times 100$.

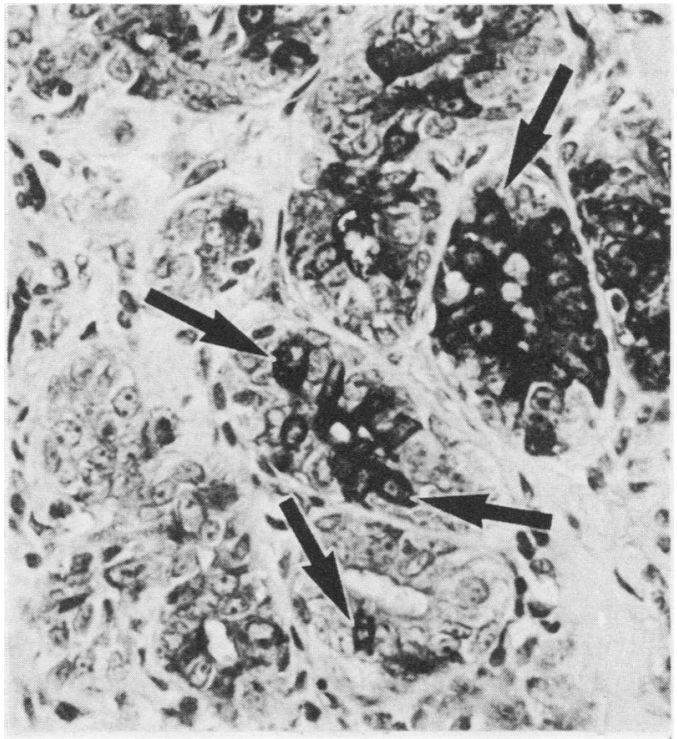

Fig. 8 Lactoferrin in adenosic area. Focal distribution of lactoferrin staining. PAP-Haematoxylin $\times 250$.

reagents: (a) methanolic hydrogen peroxide; (b) normal swine serum (Dako); (c) rabbit antihuman ferritin, transferrin or lactoferrin antiserum; (d) swine antirabbit IgG serum (Dako); (e) PAP (Dako).

After each incubation, the slides were washed with Tris-saline and placed in Tris-buffer for $20 \mathrm{~min}$. The sites of antibody binding are shown by developing the peroxidase reaction with diaminobenzidine according to Weir. ${ }^{23}$

The slides were then washed with water, counterstained with haematoxylin, dehydrated and mounted in Entellan.

The specificity of the immunohistochemical method was confirmed by the negative results obtained after omission and replacement of the antisera, and by neutralisation studies using antisera adsorbed with human ferritin and lactoferrin (Calbiochem-Behring).

\section{Results}

The results are summarised in the Table. In areas of normal and dysplastic tissue as well as in fibroadenomas, no significant immunoperoxidase staining was observed in epithelial cells. Only few macrophages in connectival stroma showed faint cytoplasmic staining. In 20 cases of carcinoma (50\%) a weak ferritin staining in few neoplastic cells was usually observed.

In connectival stroma, particularly in areas sur- 
Distribution of ferritin, transferrin and lactoferrin in benign and malignant breast lesions.

\begin{tabular}{lllll}
\hline Lesions & Ferritin & Transferrin & Lactoferrin \\
\hline Breast normal tissue & $\mathrm{E}-$ & - & +++ \\
& $\mathrm{S}+$ & $++^{*}$ & - \\
Fibroadenoma & $\mathrm{E}-$ & - & + \\
& $\mathrm{S}+$ & $++^{*}$ & - \\
Mammary dysplasia & $\mathrm{E}-$ & - & ++ \\
& $\mathrm{S}+$ & $++^{*}$ & - \\
Carcinoma & $\mathrm{E}+(50 \%)$ & $+++(20 \%)$ & - \\
& $\mathrm{S}+++$ & + & -+
\end{tabular}

$\mathrm{E}=$ epithelial component $\mathrm{S}=$ stromal component, ${ }^{*}$ Myoepithelial cells and histiocytes, $\dagger$ Only lactoferrin positive-granulocytes. $+++=$ strongly positive,$++=$ moderately positive, $+=$ weakly positive.

rounding neoplastic tissues, intensive and frequent positivities were detected in all cases, mainly located in the cytoplasm of histiocytes and spindle-shaped cells. Globular ferritin deposits were also detected in connectival stroma.

In areas of normal and dysplastic mammary tissue, spindle-shaped transferrin positive cells were sometimes arranged in a discontinuous layer at the periphery of ductules and ducts. Similar findings were often observed in ductal in situ carcinoma. In other carcinoma types, only occasional spindleshaped transferrin positive cells were detectable among neoplastic cells. In connectival stroma, histiocytic cells frequently displayed transferrin positivities with varying intensity and frequency. In eight invasive ductal carcinoma, a strong transferrin staining was observed in a variable number $(10-50 \%)$ of neoplastic cells.

Lactoferrin staining was often observed in the secretory material within the lumina, and in the cytoplasm of ductules and intralobular duct epithelial cells in areas of normal and dysplastic tissue. The higher staining intensity was mainly detected in the supranuclear region and at the cellular apex. The mammary epithelium with apocrine metaplasia was constantly negative, whereas epithelial cells in fibroadenoma and in adenosic areas displayed rare and weak positivities. In carcinomas, the immunoperoxidase staining was not observed in neoplastic cells. Only polymorphs among neoplastic cells showed strong intracytoplasmic staining.

\section{Discussion and conclusions}

Evidence for the synthesis of ferritin by lymphocytes and mononuclear-phagocytic cells was previously reported. ${ }^{2}{ }^{15}{ }^{17}$ Raised serum ferritin concentrations in malignancy as well as in rheumatoid arthritis might reflect an increase in ferritin synthesis, or a metabolic disorder in mononuclear-phagocytes cells, which accumulate ferritin though a reduction of serum iron and of transferrin saturation may occur. ${ }^{8} 10$ is

Our findings confirm this possibility since ferritin staining has been mostly observed in connectival stroma and macrophagic cells surrounding neoplastic tissue. Ferritin staining was seldom observed in neoplastic cells and only in half of carcinoma cases. Other workers, on the contrary, have suggested that hyperferritinaemia might be due to tumour synthesis. ${ }^{6} 9192122$

Nevertheless few immunohistochemical data have been reported in the literature: ferritin has been demonstrated in embryonal carcinoma cells by immunofluorescence ${ }^{21}$ and in carcinoma-in-situ of the testes by immunoperoxidase. ${ }^{9}$

It has long been known that ferritins are a family of isomeric proteins containing two subunits, termed $\mathrm{H}$ and $\mathrm{L}$, in different proportions. ${ }^{1612}$

$\mathrm{H}$ subunit is found predominantly in the so-called acidic isoferritins, which are detectable in the heart, tumours, and HeLa cells. Basic isoferritins, on the other hand, contain prevalently $\mathrm{L}$ subunits and are usually detectable in the liver and spleen tissues. The antiserum employed by us (Dako) has been raised in rabbit with human liver and spleen ferritins as immunising antigens.

Consequently, this antiserum shows a lesser reactivity for the more acidic tumour isoferritins. ${ }^{1}$ The faint ferritin staining in neoplastic cells, as detected in the present study, might be attributed to this lower reactivity.

An unexplained, prevailing transferrin localisation in myoepithelial cells has been reported. ${ }^{13}$ In the present study, this peculiar localisation appeared to be inconstant and non-specific, since transferrin staining was also detected in stromal histiocytes. In addition the presence of transferrin positivities in neoplastic cells of eight carcinoma is very intriguing. Transferrin has been identified as an obligate growing factor in serum-free conditions. ${ }^{7}$ Transferrin receptors have also been considered to be a potential marker for identifying cells undergoing divisional activity and requiring the incorporation of additional iron. ${ }^{5}{ }^{16}$ Therefore, it is tempting to speculate that transferrin staining may occur only in carcinoma and in neoplastic cells with high mitotic activity. Further studies are required to clarify these possible relations.

In the case of lactoferrin, our findings in normal breast epithelium appear to be in agreement with several papers which have provided immunohistochemical evidence for the presence of this protein in glandular tissue of different organs..$^{13}{ }^{1420}$ The lack of lactoferrin staining in all of 40 breast carcinoma suggests that this protein might be considered as a 
potential marker of benign lesions.

We wish to thank Mr Gennaro Chiappetta for technical assistance and Mr Rosario Romanelli for their expert photographic work.

This study was partially funded by the Associazione Nazionale per le Ricerche sul Cancro.

\section{References}

${ }^{1}$ Arosio P, Yokota M, Drysdale JW. Structural and immunological relationships of isoferritins in normal and malignant cells Cancer Res 1976;36;1735-43.

${ }^{2}$ Dörner MH, Silverstone A, Nishiya K, De Sostoa A, De Sousa M. Ferritin synthesis by human $\mathrm{T}$ lymphocytes. Science 1980;209:1019-21.

${ }^{3}$ Faulk WP, Hsi Bae-Li, Stevens PJ. Transferrin and transferrin receptor in carcinoma of the breast. Lancet 1980;i:390-2.

${ }^{4}$ Giordano GG, Rossiello R, Bevilacqua AM, Carriero MV. Multiparametric characterization of colon-rectum carcinoma: histopathology, histochemistry and immunohistochemistry. Med Biol Environ 1981;9:387-97.

${ }^{5}$ Hamilton TA, Wada HG, Sussman HH. Identification of transferrin receptors on the surface of human cultured cells. Proc Natl Acad Sci USA 1979;76:6406-10.

' Hazard JT, Drysdale JW. Ferritinaemia in cancer. Nature 1977;265:755-6.

' Hutchings SE, Sato GH. Growth and maintenance if He-La cells in serum-free medium supplemented with hormones. Proc Natl Acad Sci USA 1978;75:901-4.

${ }^{8}$ Jacobs A, Jones B, Ricketts C, Bulbrook RD, Wang DY. Serum ferritin concentration in early breast cancer. $\mathrm{Br} J$ Cancer 1976;34:286-90.

- Jacobson GK, Jacobson M, Clausen PP. Ferrin as a possible marker protein of carcinoma in situ of the testis. Lancet 1980;ii:533-4.

${ }^{10}$ Jones PAE, Miller FM, Worwood M, Jacobs A. Ferritinaemia in leukaemia and Hodgkin's disease. Br J Cancer 1973;27:212-7.

" Lamoureux G, Manderville R, Poisson R, Poisson-Legault S, Jolicoeur R. Biologic Markers and Breast Cancer. A multiparametric study. Increased serum protein levels. Cancer 1982;49:502-12.
${ }^{12}$ Marcus DM, Zinberg N. Measurement of serum ferritin by Radioimmunoassay: results in normal individuals and patients with breast cancer. J Natl Cancer Inst 1975;55:791-5.

${ }^{13}$ Mason DY, Taylor CR. Distribution of transferrin, ferritin and lactoferrin in human tissues. J Clin Pathol 1978;31:316-27.

${ }^{14}$ Masson PL, Heremans JF. Studies on lactoferrin, the iron binding protein of secretions. Prot biol fl 1966;14:115-24.

is Sarcione EJ, Smalley JR, Lema MJ, Stutzman L. Increased ferritin synthesis and release by Hodgkin's disease peripheral blood lymphocytes. Int J Cancer 1977;20:339-46.

${ }^{16}$ Shindleman JE, Ortmeyer AE, Sussman HH. Demonstration of the transferrin receptor in human breast cancer tissue. Potential marker for identifying dividing cells. Int J Cancer 1981;27:32934.

"Summers M, White G, Jacobs A. Ferritin synthesis in lymphocytes, polymorphs and monocytes. $\mathrm{Br} J$ Haematol 1973;30:425-34.

${ }^{18}$ Taylor CR. An immunohistological study of follicular lymphoma, reticulum cell sarcoma and Hodgkin's disease. Eur J Cancer 1976;12:61-75.

${ }^{19}$ Tomoda H, Furusawa M, Sco Y, Matsukuchi T, Miyazaki M, Kanashima $R$. Measurement of serum ferritin in various digestive disease by reversed passive hemagglutination using anti-human placental ferritin antiserum. Jpn J Clin Oncol 1982;12:9-16.

${ }^{20}$ Tourville DR, Ogra SS, Lippes J, Tomasi TB. The human female reproductive tract: immunohistological localization of $A, G, M$, secretory "piece" and lactoferrin. Am J Obstet Gynecol 1970;108:1102-8.

${ }^{21}$ Wahren B, Alpert E, Esposti P. Multiple antigens as marker substances in germinal tumours of the testis. $J$ Natl Cancer Inst 1977;58:489-95.

22 Weinstein RE, Bounds BH, Silberberg BK. Tissue ferritin concentration in carcinoma of the breast. Cancer 1982;50:24069.

${ }^{23}$ Weir EE, Pretlow TG, Pitts A, Williams EE. A more sensitive and specific histochemical peroxidase stain for the localization of cellular antigen by the enzyme-antibody conjugate method. J Histochem Cytochem 1974;22:1135-40.

Requests for reprints to: Prof Giovan Giacomo Giordano, Chief, Division of Anatomic Pathology, Istituto Nazionale dei Tumori di Napoli, Via Mariano Semmola, Cappella dei Cangiani, 80131 Napoli, Italy. 